\author{
F. Angelico $\cdot$ C. Alessandri $\cdot$ D. Ferro \\ P. Pignatelli $\cdot$ M. Del Ben $\cdot$ S. Fiorello \\ R. Cangemi $\cdot$ L. Loffredo $\cdot$ F. Violi
}

\title{
Enhanced soluble CD40L in patients with the metabolic syndrome: relationship with in vivo thrombin generation
}

Received: 10 November 2005 / Accepted: 2 February 2006 / Published online: 29 March 2006

C) Springer-Verlag 2006

\begin{abstract}
Aims/hypothesis: The metabolic syndrome is associated with proinflammatory and prothrombotic states. This study was designed to assess the behaviour of soluble CD40 ligand (sCD40L) and prothrombin fragment $F_{1+2}$, a marker of thrombin generation, in patients with the metabolic syndrome. Methods: We investigated 106 patients with the metabolic syndrome, diagnosed according to the ATPIII report, and 104 subjects without the metabolic syndrome. Results: Plasma values of sCD40L and $F_{1+2}$ were higher in patients with the metabolic syndrome $(4.11 \pm 1.64 \mathrm{vs} 2.61 \pm 0.89 \mathrm{ng} / \mathrm{ml}$ and $1.54 \pm 0.49$ vs $0.87 \pm 0.21 \mathrm{nmol} / 1$, respectively; $p<0.001)$ and were significantly correlated $(r=0.925, \quad p<0.001)$. Stepwise multiple linear regression analysis showed that sCD40L was significantly associated with $F_{1+2}$, female sex and waist circumference. Conclusions/interpretation: $\mathrm{Pa}-$ tients with the metabolic syndrome have enhanced values of plasma sCD40L and $F_{1+2}$. The study provides further insight into the relationship between metabolic syndrome, inflammation and thrombosis.
\end{abstract}

Keywords Atherosclerosis - Coagulation - Inflammation · Metabolic syndrome $\cdot \mathrm{sCD} 40 \mathrm{~L}$

Abbreviations ATP III: The National Cholesterol Education Program's Adult Treatment Panel III report . CD40L: CD40 ligand - CRP: C-reactive protein - CVD: cardiovascular disease $\cdot \mathrm{sCD}^{\mathrm{S}} 4 \mathrm{~L}$ : soluble CD40 ligand

\footnotetext{
F. Angelico · C. Alessandri - D. Ferro ·

P. Pignatelli · M. Del Ben - S. Fiorello ·

R. Cangemi $\cdot$ L. Loffredo $\cdot$ F. Violi $(\bowtie)$

IV Division of Internal Medicine,

Department of Experimental Medicine and Pathology,

University of Rome 'La Sapienza',

Viale del Policlinico,

00161 Rome, Italy

e-mail: francesco.violi@uniroma1.it

Tel.: +39-06-49972249

Fax: +39-06-49970211
}

\section{Introduction}

The metabolic syndrome is an emerging disorder associated with accelerated atherosclerosis and characterised by a constellation of metabolic and non-metabolic cardiovascular risk factors. Thus, metabolic syndrome patients have a higher risk of cardiovascular disease (CVD) than people without the syndrome [1-8]. In the Framingham study, metabolic syndrome alone predicts about $25 \%$ of new CVD cases $[4,9]$. The risk of CVD is elevated in men with metabolic syndrome, with a 10 -year risk ranging from 10 to 20\% [9]; CVD risk is apparently less in women with metabolic syndrome, but it is unclear if patient selection may account for this difference [9]. The National Cholesterol Education Program's Adult Treatment Panel III report (ATP III) [10] identified six components of metabolic syndrome that may predispose to CVD: (1) abdominal obesity; (2) atherogenic dyslipidaemia; (3) raised blood pressure; (4) insulin resistance $+/-$ glucose intolerance; (5) proinflammatory state; and (6) prothrombotic state.

As far as the prothrombotic state is concerned, patients with metabolic syndrome are characterised by elevated fibrinogen and plasminogen activator inhibitor 1 [11], which could be linked to enhanced clotting activation; however, it is not clear if this occurs in vivo and the underlying mechanism is unknown. CD40 ligand (CD40L) is a component of the TNF family that, upon engagement with its receptor CD40, elicits a series of inflammatory and prothrombotic responses including overexpression of adhesive proteins, chemokines, metalloproteinases and tissue factor [12-14]. Several cell lines express CD40L including lymphocytes and cells of the vascular system such as endothelial cells, smooth muscle cells, monocytes and platelets $[13,14]$. Platelets express CD40L on their surface upon stimulation with agonists such as thrombin and collagen; CD40L is then cleaved and circulates as soluble CD40L (sCD40L) [12]. It is calculated that more than 95\% of circulating $\mathrm{SCD} 40 \mathrm{~L}$ is of platelet origin [15].

Recent studies demonstrated that SCD40L is enhanced in patients at risk of CVD and in those with acute coronary syndrome suggesting that it may represent a new marker of 
atherosclerotic progression [16-20]. The behaviour of sCD40L has never been explored in patients with metabolic syndrome. The aim of the present study was, therefore, to investigate the behaviour of plasma sCD40L levels in patients with metabolic syndrome. Furthermore, we sought to determine if, in this setting, a relationship exists between SCD40L and clotting activation.

\section{Methods}

Subjects

The study was carried out in 210 patients (110 men, age $56.1 \pm 11.3$ years and 100 women, age $53.4 \pm 11.8$ years) presenting for suspected metabolic disorders in our metabolic outpatient clinic between March 2003 and January 2004. All patients had a complete clinical and biochemical work-up as part of the routine clinical examination.

Written consent was obtained from all subjects before the study and the study conformed to the ethical guidelines of the 1975 Declaration of Helsinki. The exclusion criteria were cancer, liver or kidney diseases, acute or chronic inflammatory disorders and CVD.

Following the criteria of the ATP III [10], metabolic syndrome was diagnosed in 106 of the 210 subjects, on the concomitant presence of at least three of the following five clinical features: waist circumference (central obesity) $>102 \mathrm{~cm}$ in men and $>88 \mathrm{~cm}$ in women, fasting blood glucose $\geq 6.105 \mathrm{mmol} / \mathrm{l}$, triglycerides $\geq 1.695 \mathrm{mmol} / 1$, HDL-cholesterol $<1.036 \mathrm{mmol} / 1$ in men and $<1.295 \mathrm{mmol} / \mathrm{l}$ in women, arterial systolic/ diastolic blood pressure $\geq 130 / \geq 85 \mathrm{mmHg}$.

One hundred and four subjects (50 men, age $56.7 \pm$ 12.9 years and 54 women, age $49.4 \pm 13.0$ years) who did not meet the above criteria for the diagnosis of metabolic syndrome were considered to be subjects without metabolic syndrome. In this last group, $17.3 \%$ had abdominal obesity, 25\% had low HDL-cholesterol, $14.4 \%$ had high triglycerides, $22.1 \%$ had high blood pressure and $4.8 \%$ had high fasting glucose.

Arterial blood pressure was measured on the right arm with the subjects in a sitting position and after a 5-min rest, using a mercury sphygmomanometer: the average of two measurements, 1 min apart, was considered. Waist circumference, height and weight were recorded with subjects wearing light clothing, without shoes and BMI was calculated as weight $(\mathrm{kg})$ divided by the square of the height $\left(\mathrm{m}^{2}\right)$. A detailed history of previous cardiovascular events and of current medication was recorded.

Diabetes was diagnosed according to the World Health Organization (WHO) criteria [21]. Subjects taking insulin or oral antidiabetic drugs were considered to have diabetes.

Table 1 Clinical characteristics of patients with and without the metabolic syndrome

\begin{tabular}{|c|c|c|c|}
\hline \multirow[t]{2}{*}{ Variable } & \multicolumn{2}{|c|}{ Metabolic syndrome } & \multirow[t]{2}{*}{$p$ value } \\
\hline & NO $n=104$ & YES $n=106$ & \\
\hline Mean age (years) & $55.35 \pm 12.32$ & $54.94 \pm 10.6$ & $0.796^{\mathrm{c}}$ \\
\hline sCD40L (ng/ml) & $2.61 \pm 0.89$ & $4.11 \pm 1.64$ & $<0.001^{\mathrm{c}}$ \\
\hline$F_{1+2}(\mathrm{nmol} / \mathrm{l})$ & $0.87 \pm 0.21$ & $1.54 \pm 0.49$ & $<0.001^{\mathrm{c}}$ \\
\hline Men $(\%)$ & 48.1 & 56.6 & $0.272^{\mathrm{d}}$ \\
\hline Central obesity $(\%)^{\mathrm{a}}$ & 17.3 & 94.3 & N/A \\
\hline Low HDL-cholesterol (\%) ${ }^{\mathrm{a}}$ & 25.0 & 65.0 & N/A \\
\hline High triglycerides $(\%)^{\mathrm{a}}$ & 14.4 & 69.8 & $\mathrm{~N} / \mathrm{A}$ \\
\hline C-reactive protein $(\mathrm{mg} / \mathrm{l})^{\mathrm{b}}$ & $0.8(0.2-2.9)$ & $2.1(0.6-3.9)$ & $<0.001$ \\
\hline Fibrinogen $(\mathrm{mmol} / \mathrm{l})$ & $8.40 \pm 0.62$ & $8.50 \pm 0.74$ & 0.333 \\
\hline Leucocyte count $\left(\times 1000 / \mathrm{mm}^{3}\right)$ & $6.86 \pm 1.93$ & $6.90 \pm 1.85$ & 0.878 \\
\hline High blood pressure $(\%)^{\mathrm{a}}$ & 22.1 & 90.5 & $\mathrm{~N} / \mathrm{A}$ \\
\hline Hyperglycaemia $(\%)^{\mathrm{a}}$ & 4.8 & 37.7 & N/A \\
\hline Diabetes mellitus (\%) & 4.8 & 30.1 & $<0.001^{\mathrm{d}}$ \\
\hline \multicolumn{4}{|l|}{ Medication (\%) } \\
\hline Statins/fibrates & 1.9 & 11.3 & $0.014^{\mathrm{d}}$ \\
\hline Antihypertensives & 10.5 & 52.8 & $<0.001^{\mathrm{d}}$ \\
\hline Metformin & 1.9 & 12.2 & $0.008^{\mathrm{e}}$ \\
\hline Aspirin & 2.8 & 9.4 & $0.057^{\mathrm{e}}$ \\
\hline Ticlopidine & 0 & 5.0 & \\
\hline
\end{tabular}

N/A Not applicable because criteria for selection of cases are based on these parameters

${ }^{a}$ Defined according to the ATP III criteria

${ }^{\mathrm{b}}$ Data expressed as median and interquartile range

'Unpaired Student's $t$-test

$\mathrm{d} \chi^{2}$ test

'Fisher's exact test 
Blood sampling protocol

Subjects underwent routine biochemical evaluations including fasting total and HDL-cholesterol, triglycerides, glucose and insulin; glucose and insulin levels were also recorded during a standard (75-g) oral glucose tolerance test.

After overnight fasting and supine rest for at least $10 \mathrm{~min}$, blood samples were taken into tubes containing 3.8\% trisodium citrate and centrifuged at $5,000 \times g$ for $10 \mathrm{~min}$ to obtain plasma, which was stored at $-80^{\circ} \mathrm{C}$ until use.

Analysis of circulating levels of sCD40L and $F_{1+2}$

Plasma levels of sCD40L were measured by an immunoassay (Quantikine CD40 ligand R\&D Systems, Minneapolis, MN, USA). Intra- and inter-assay coefficients of variation were 7 and $10 \%$, respectively.

Plasma levels of prothrombin fragment $F_{1+2}$ were assayed by an enzyme immunoassay based on the sandwich principle (Enzygnost $F_{1+2}$; Behringwerke, Marburg, Germany) Intra- and inter-assay coefficients of variation were 8 and $9 \%$, respectively.

Lower limits of detection for sCD40L and $F_{1+2}$ were $0.10 \mathrm{ng} / \mathrm{ml}$ and $0.04 \mathrm{nmol} / \mathrm{l}$, respectively.

Plasma fibrinogen was evaluated according to the Clauss method (Instrumentation Laboratory, Milan, Italy) employing the Electra 1400C coagulometer (Instrumentation Laboratory) [22]. Intra- and inter-assay coefficients of variation were 6 and 7\%, respectively.

Serum high-sensitivity C-reactive protein (CRP) was assayed by an immunonephelometric method (N-High Sensitivity CRP, Dade Behring Marburg Gmbh, Germany). Intra- and inter-assay coefficients of variation were 3 and $2.5 \%$, respectively.

Table 2 Bivariate analysis (Spearman's test) — correlation between sCD40L and all other parameters evaluated

\begin{tabular}{lcc}
\hline Variable & $r$ & \multicolumn{1}{l}{$r$} \\
\hline Age & -0.104 & 0.291 \\
BMI & 0.210 & 0.210 \\
$F_{1+2}$ & 0.925 & $<0.001$ \\
C-reactive protein & 0.068 & 0.509 \\
Fibrinogen & 0.249 & 0.210 \\
Leucocyte count & 0.003 & 0.979 \\
Waist circumference & 0.02 & 0.787 \\
Systolic blood pressure & -0.059 & 0.552 \\
Diastolic blood pressure & -0.064 & 0.522 \\
Total cholesterol & 0.023 & 0.812 \\
LDL cholesterol & 0.047 & 0.631 \\
HDL cholesterol & 0.224 & 0.210 \\
Triglycerides & -0.114 & 0.244 \\
Glycaemia & -0.167 & 0.089 \\
Insulin & 0.035 & 0.771 \\
\hline
\end{tabular}

Power calculations

Assuming that patients with metabolic syndrome had a $30 \%$ increase of $\mathrm{sCD} 40 \mathrm{~L}$ compared to controls we postulated that the study sample should consist of at least 42 patients for each group $(\alpha=0.05$ and $1-\beta=0.80)$.

\section{Data analysis}

Categorical variables are reported as counts (percentage) and continuous variables as means $\pm \mathrm{SD}$ unless otherwise indicated. Comparisons between groups were carried out by Student's $t$-test and were replicated as appropriate with nonparametric tests (Kolmogorov-Smirnov $(z)$ test) in cases where variances were non-homogeneous as verified by Levene's test. Proportions and categorical variables were tested by the $\chi^{2}$-test and by the two-tailed Fisher's exact method when appropriate. Non-normal data, presented as median and interquartile range, were analysed by the MannWhitney $U$ test (two groups). Bivariate analysis was performed with a Spearman correlation test. Multiple linear regression analysis was performed using a stepwise selection method and was performed to determine the independent parameters of $\mathrm{sCD} 40 \mathrm{~L}$ adjusted for blood pressure, glycaemia, insulin, cholesterol, age, sex and triglycerides.

A value of $p<0.05$ was considered statistically significant. All analyses were carried out using SPSS-13.0 software.

\section{Results}

The clinical characteristics of the 210 subjects with and without metabolic syndrome are summarised in Table 1. Prevalence of all the risk factors taken into consideration for the diagnosis of metabolic syndrome was significantly higher in the group of metabolic syndrome patients. In this

Table 3 Bivariate analysis (Spearman's test) — correlation between $F_{1+2}$ and all other parameters evaluated

\begin{tabular}{lrr}
\hline Variable & \multicolumn{2}{l}{$r$} \\
\hline Age & -0.109 & 0.291 \\
BMI & 0.104 & 0.265 \\
sCD40L & 0.925 & $<0.001$ \\
C-reactive protein & -0.003 & 0.973 \\
Fibrinogen & 0.201 & 0.315 \\
Leucocyte count & 0.028 & 0.774 \\
Waist circumference & -0.018 & 0.859 \\
Systolic blood pressure & 0.035 & 0.725 \\
Diastolic blood pressure & -0.008 & 0.940 \\
Total cholesterol & 0.026 & 0.795 \\
LDL cholesterol & 0.034 & 0.728 \\
HDL cholesterol & 0.218 & 0.253 \\
Triglycerides & -0.076 & 0.437 \\
Glycaemia & -0.194 & 0.059 \\
Insulin & 0.070 & 0.560 \\
\hline
\end{tabular}




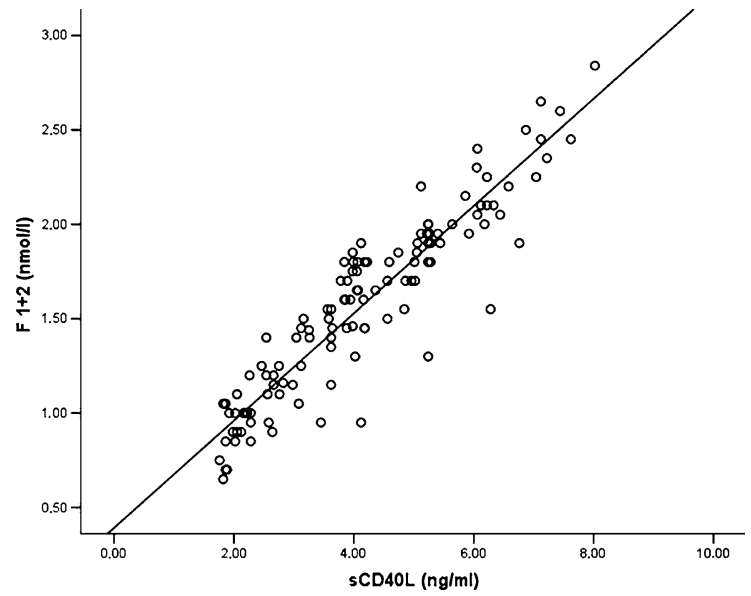

Fig. 1 Correlation between $\mathrm{sCD} 40 \mathrm{~L}$ and $F_{1+2}$ in metabolic syndrome patients $(n=106)$

group, virtually all subjects had abdominal obesity and elevated blood pressure values, about two-thirds had low HDL-cholesterol and elevated triglyceride levels, while $<40 \%$ had hyperglycaemia.

Both mean plasma sCD40L and $F_{1+2}$ were significantly higher $(p<0.001)$ in subjects with metabolic syndrome than in subjects without (mean \pm SD: $4.11 \pm 1.64$ vs $2.61 \pm 0.89$ $\mathrm{ng} / \mathrm{ml}$ and $1.54 \pm 0.49 \mathrm{vs} 0.87 \pm 0.21 \mathrm{nmol} / \mathrm{l}$, respectively); these results persisted also when patients treated with statins/fibrates were excluded (not shown).

There was a significant trend for an increasing percentage of patients with metabolic syndrome across the quartiles of the distributions of both sCD40L (from $26.9 \%, 14$ of 52 patients, in the lower quartile to $98.0 \%, 51$ of 52 patients, in the highest quartile, linear trend test, $\chi^{2}=58.7, p<0.0001$ ) and $F_{1+2}$ (from $7.6 \%$, four of 52 patients, in the lower quartile to $100 \%, 52$ of 52 patients, in the highest quartile, linear trend test, $\chi^{2}=95.3, p<0.0001$ ).

Women with metabolic syndrome had higher values of sCD40L $(4.86 \pm 1.65$ vs $3.54 \pm 1.39 \mathrm{ng} / \mathrm{ml}, p<0.001)$ and $F_{1+2}(1.72 \pm 0.52$ vs $1.40 \pm 0.43 \mathrm{nmol} / 1, p=0.001)$ than men with metabolic syndrome. Similar findings were observed in subjects without metabolic syndrome (not shown).

CRP levels were significantly higher in subjects with than in subjects without metabolic syndrome (median 2.1, interquartile range: $0.6-3.9 \mathrm{mg} / \mathrm{l}$ vs median 0.8 , interquartile range: $0.2-2.9 \mathrm{mg} / \mathrm{l})$. CRP levels were not significantly correlated with SCD40L $(r=0.068)$ and $F_{1+2}$ $(r=-0.003)$ (Tables 2 and 3).

On bivariate analysis, in metabolic syndrome patients, sCD40L plasma levels were significantly correlated with
$F_{1+2}$ plasma values $(r=0.925, p<0.001)$ (Fig. 1, Table 2$)$. A similar finding was seen when $F_{1+2}$ plasma levels were used as the dependent variable (Table 3 ).

The analysis of other markers of inflammation and atherothrombosis, including leucocyte count and fibrinogen, disclosed no difference between patients with metabolic syndrome and controls (Table 1).

To further define the relationship between $\mathrm{SCD} 40 \mathrm{~L}$ and metabolic syndrome, stepwise multiple linear regression analysis including the five components of metabolic syndrome, was determined (Table 4); in this analysis we also included sex, age, $F_{1+2}$ and CRP. Among the components of metabolic syndrome, sCD40L was associated only with abdominal obesity; sCD40L was also significantly associated with $F_{1+2}$ and with female sex. Stepwise regression analysis, repeated using $F_{1+2}$ as dependent variable, showed a significant association only with sCD40L plasma values (B: 0.298; E.S.: 0.012; standardised coefficient $\beta$ : $0.967 ; p<0.001)$.

No significant difference was found in SCD40L, $F_{1+2}$, fibrinogen and CRP plasma levels among metabolic syndrome patients with or without statin, anti-hypertensive therapy and/or anti-diabetic treatment.

Recently, a new classification was proposed by the International Diabetes Federation; in this classification, they considered that abdominal obesity is so highly correlated with insulin resistance that it is unnecessary to measure insulin resistance although the presence of abdominal obesity is necessary for diagnosis [23].

When evaluated on the basis of this new classification, the results reported above did not change (not shown).

\section{Discussion}

This study provides the first evidence that patients with metabolic syndrome have enhanced values of sCD40L, which are significantly correlated with $F_{1+2}$ plasma levels, thus suggesting a link between platelet and clotting activation. The close association between sCD40L and $F_{1+2}$ has already been described in other atherosclerotic settings such as hypercholesterolaemia and diabetes [2426], leading to the hypothesis that CD40L overexpression may be a stimulus for clotting activation. This hypothesis is based on previous studies [27-31] demonstrating that in monocytes, endothelial cells and smooth muscle cells CD40L overexpresses tissue factor, a glycoprotein of the extrinsic clotting pathway that triggers the coagulation cascade activating factor VII and in turn converts factor X to Xa. Therefore, it is possible that the overexpression of

Table 4 Stepwise multiple linear regression analysis with sCD40L as the dependent variable in patients with metabolic syndrome

\begin{tabular}{lllllr}
\hline Variable & $n$ & $B$ & SE & Coefficient $\beta$ & $p$ \\
\hline$F_{1+2}$ & 106 & 2.913 & 0.120 & 0.897 & $<0.001$ \\
Female sex & 106 & 0.481 & 0.148 & 0.126 & 0.001 \\
Waist circumference & 106 & 0.010 & 0.005 & 0.079 & 0.040 \\
\hline
\end{tabular}

Adjusted for age, CRP, blood pressure, glycaemia, insulin, cholesterol (total, LDL, HDL cholesterol), triglycerides 
CD40L may favour the activation of the clotting system via overproduction of tissue factor. This hypothesis has been recently supported by our group, which demonstrated that CD40L levels as low as $50 \mathrm{ng} / \mathrm{ml}$ are able to overexpress monocyte tissue factor and in turn enhance the plasma levels of $F_{1+2}$. Activation of the clotting system by CD40L was not observed in monocytes taken from patients with hereditary deficiency of gp91phox, the central core of NADPH oxidase, which indicated that clotting activation by CD40L is mediated by oxidative stress [32]. Although both men and women with metabolic syndrome had elevated plasma sCD40L and $F_{1+2}$ values, women had significantly higher values than men. This finding is in accordance with a recent study by Varo et al. [33] who measured plasma sCD40L in a population affected by type 1 and type 2 diabetes mellitus. They found similar values of SCD40L in men and women affected by type 1 diabetes, but in patients with type 2 diabetes women had higher values than men. The mechanism through which women with metabolic syndrome have higher values of sCD40L than men is unknown and deserves further investigation. This finding, however, does not seem to be the result of chance because similar findings were seen with the prothrombin fragment $F_{1+2}$. Indeed, patients with metabolic syndrome had higher values of $F_{1+2}$ than subjects without metabolic syndrome, but, again, women had higher values then men. A gender difference in blood thrombogenicity has also been observed in patients with hypercholesterolaemia, in whom the prothrombin fragment $F_{1+2}$ was higher in women than men [34].

Multiple regression analysis revealed that among the five components of metabolic syndrome sCD40L was only significantly associated with abdominal obesity. This finding, suggesting that obesity may promote CD40L overexpression, is consistent with a previous study showing that SCD40L plasma values are elevated in obese men and decrease concomitantly with BMI reduction [35].

Adipose tissue has emerged as a key secretory organ that may regulate CD40L expression [36]. Accordingly, adipocytes secrete resistin which lowers TNF receptorassociated factor 3, a key inhibitor of CD40 signalling in endothelial cells [36]. Further study is therefore necessary to investigate if $\mathrm{CD} 40 \mathrm{~L}$ upregulation is mediated by resistin in metabolic syndrome. Whatever the mechanism, the overexpression of CD40L and its relationship with enhanced clotting activation may be of relevance to explain the accelerated atherosclerosis of patients with metabolic syndrome. Thus, there is emerging evidence that CD40L plays a pivotal role in the initiation and progression of atherosclerotic disease $[13,14]$. In hypercholesterolaemic mice, inhibition of CD40L by a specific antibody retards the formation and progression of atherosclerotic plaque [37]. Moreover, inhibition of CD40L engagement with its receptor promotes changes in the atherosclerotic plaque, that are characterised by the presence of lesions that are less prone to rupture $[14,38]$. Finally, CD40L is also implicated in the thrombotic process as shown by the poor stability of thrombus in the absence of CD40L and its restoration after the infusion of recombinant SCD40L [39].

Cross-sectional and prospective studies demonstrated that $\mathrm{SCD} 40 \mathrm{~L}$ is increased in patients with cardiovascular risk factors or acute coronary syndromes and is predictive of future cardiovascular events in patients with and without cardiovascular events. In the present study we did not find any difference in SCD40L between patients with and without a clinical history of cardiovascular disease; however, the small sample size and the retrospective nature of this analysis limit any conclusion; prospective studies should be carried out to evaluate the role of CD40L in the process of atherosclerosis occurring in patients with metabolic syndrome.

In conclusion, this study shows that CD40L overexpression may represent a novel mechanism that accounts for the prothrombotic state of patients with metabolic syndrome. This represents a new insight into the physiopathology of the accelerated atherosclerosis that characterises this clinical setting.

\section{References}

1. Pyorala M, Miettinen H, Halonen P, Laakso M, Pyorala K (2000) Insulin resistance syndrome predicts the risk of coronary heart disease and stroke in healthy middle-aged men: the 22year follow-up results of the Helsinki Policemen Study. Arterioscler Thromb Vasc Biol 20:538-544

2. Isomaa B, Almgren P, Tuomi T et al (2001) Cardiovascular morbidity and mortality associated with the metabolic syndrome. Diabetes Care 24:683-689

3. Lakka HM, Laaksonen DE, Lakka TA et al (2002) The metabolic syndrome and total and cardiovascular disease mortality in middle-aged men. JAMA 288:2709-2716

4. Klein BE, Klein R, Lee KE (2002) Components of the metabolic syndrome and risk of cardiovascular disease and diabetes in beaver dam. Diabetes Care 25:1790-1794

5. Sattar N, Gaw A, Scherbakova O et al (2003) Metabolic syndrome with and without C-reactive protein as a predictor of coronary heart disease and diabetes in the West of Scotland Coronary Prevention Study. Circulation 108:414-419

6. Bonora E, Kiechl S, Willeit J et al (2003) Carotid atherosclerosis and coronary heart disease in the metabolic syndrome: prospective data from the Bruneck study. Diabetes Care 26:1251-1257

7. Ninomiya JK, L'Italien G, Criqui MH, Whyte JL, Gamst A, Chen RS (2004) Association of the metabolic syndrome with history of myocardial infarction and stroke in the third national health and nutrition examination survey. Circulation 109:42-46

8. Girman CJ, Rhodes T, Mercuri M et al (2004) The metabolic syndrome and risk of major coronary events in the Scandinavian Simvastatin Survival Study (4S) and the Air Force/Texas Coronary Atherosclerosis Prevention Study (AFCAPS/TexCAPS). Am J Cardiol 93:136-141

9. Grundy SM, Brewer HB Jr, Cleeman JI, Smith SC Jr, Lenfant C (2004) Definition of metabolic syndrome: report of the National Heart, Lung, and Blood Institute/American Heart Association conference on scientific issues related to definition. Circulation 109:433-438

10. National Cholesterol Education Program (NCEP) Expert Panel on Detection, Evaluation, and Treatment of High Blood Cholesterol in Adults (Adult Treatment Panel III) (2002) Third report of the National Cholesterol Education Program (NCEP) Expert Panel on Detection, Evaluation, and Treatment of High Blood Cholesterol in Adults (Adult Treatment Panel III) final report. Circulation 106:3143-3421 
11. Freeman MS, Mansfield MW, Barrett JH, Grant PJ (2003) Insulin resistance: an atherothrombotic syndrome. The Leeds family study. Thromb Haemost 89:161-168

12. Henn V, Slupsky JR, Grafe M et al (1998) CD40 ligand on activated platelets triggers an inflammatory reaction of endothelial cells. Nature 391:591-594

13. Schonbeck U, Libby P (2001) CD40 signaling and plaque instability. Circ Res 89:1092-1103

14. Lutgens E, Daemen MJ (2002) CD40-CD40L interactions in atherosclerosis. Trends Cardiovasc Med 12:27-32

15. Andre P, Nannizzi-Alaimo L, Prasad SK, Phillips DR (2002) Platelet-derived CD40L: the switch-hitting player of cardiovascular disease. Circulation 106:896-899

16. Schonbeck U, Varo N, Libby P, Buring J, Ridker PM (2001) Soluble CD40L and cardiovascular risk in women. Circulation 104:2266-2268

17. Garlichs CD, Kozina S, Fateh-Moghadam S et al (2003) Upregulation of CD40-CD40 ligand (CD154) in patients with acute cerebral ischemia. Stroke 34:1412-1418

18. Heeschen C, Dimmeler S, Hamm CW et al (2003) Soluble CD40 ligand in acute coronary syndromes. N Engl J Med 348:1104-1111

19. Varo N, de Lemos JA, Libby P et al (2003) Soluble CD40L: risk prediction after acute coronary syndromes. Circulation 108:1049-1052

20. Aukrust P, Muller F, Ueland T et al (1999) Enhanced levels of soluble and membrane-bound CD40 ligand in patients with unstable angina. Possible reflection of $\mathrm{T}$ lymphocyte and platelet involvement in the pathogenesis of acute coronary syndromes. Circulation 100:614-620

21. Alberti KG, Zimmet PZ (1998) Definition, diagnosis and classification of diabetes mellitus and its complications. Part 1: diagnosis and classification of diabetes mellitus provisional report of a WHO consultation. Diabet Med 15:539-553

22. Clauss A (1957) Gerinnungsphysiologische Schnellmethode zur Bestimmung des Fibrinogens. Acta Haematol 17:237-240

23. IDF: International Diabetes Federation. Worldwide definition of the metabolic syndrome. Available at: http://www.idf.org/ webdata/docs/IDF Metasyndrome_definition.pdf. Accessed August 24, 2005

24. Sanguigni V, Pignatelli P, Lenti L et al (2005) Short-term treatment with atorvastatin reduces platelet CD40 ligand and thrombin generation in hypercholesterolemic patients. Circulation 111:412-419

25. Cipollone F, Chiarelli F, Davi G et al (2005) Enhanced soluble CD40 ligand contributes to endothelial cell dysfunction in vitro and monocyte activation in patients with diabetes mellitus: effect of improved metabolic control. Diabetologia 48:1216-1224
26. Aso $\mathrm{Y}$, Fujiwara $\mathrm{Y}$, Tayama $\mathrm{K}$, Takebayashi $\mathrm{K}$, Inukai $\mathrm{T}$, Takemura Y (2000) Relationship between soluble thrombomodulin in plasma and coagulation or fibrinolysis in type 2 diabetes. Clin Chim Acta 301:135-145

27. Mach F, Schonbeck U, Bonnefoy JY, Pober JS, Libby P (1997) Activation of monocyte/macrophage functions related to acute atheroma complication by ligation of CD40: induction of collagenase, stromelysin, and tissue factor. Circulation 96:396-399

28. Zhou L, Stordeur P, de Lavareille A et al (1998) CD40 engagement on endothelial cells promotes tissue factor-dependent procoagulant activity. Thromb Haemost 79:1025-1028

29. Miller DL, Yaron R, Yellin MJ (1998) CD40L-CD40 interactions regulate endothelial cell surface tissue factor and thrombomodulin expression. J Leukoc Biol 63:373-379

30. Slupsky JR, Kalbas M, Willuweit A, Henn V, Kroczek RA, Muller-Berghaus G (1998) Activated platelets induce tissue factor expression on human umbilical vein endothelial cells by ligation of CD40. Thromb Haemost 80:1008-1014

31. Schonbeck U, Mach F, Sukhova GK et al (2000) CD40 ligation induces tissue factor expression in human vascular smooth muscle cells. Am J Pathol 156:7-14

32. Sanguigni V, Ferro D, Pignatelli P et al (2005) CD40 ligand enhances monocyte tissue factor expression and thrombin generation via oxidate stress in patients with hypercholesterolemia. J Am Coll Cardiol 45:35-42

33. Varo N, Vicent D, Libby P et al (2003) Elevated plasma levels of the atherogenic mediator soluble CD40 ligand in diabetic patients: a novel target of thiazolidinediones. Circulation 107:2664-2669

34. Dangas G, Smith DA, Badimon JJ et al (1999) Gender differences in blood thrombogenicity in hyperlipidemic patients and response to pravastatin. Am J Cardiol 84:639-643

35. Desideri G, Ferri C (2003) Effects of obesity and weight loss on soluble CD40L levels. JAMA 289:1781-1782

36. Verma S, Li SH, Wang CH et al (2003) Resistin promotes endothelial cell activation: further evidence of adipokineendothelial interaction. Circulation 108:736-740

37. Mach F, Schonbeck U, Sukhova GK, Atkinson E, Libby P (1998) Reduction of atherosclerosis in mice by inhibition of CD40 signalling. Nature 394:200-203

38. Schonbeck U, Sukhova GK, Shimizu K, Mach F, Libby P (2000) Inhibition of CD40 signaling limits evolution of established atherosclerosis in mice. Proc Natl Acad Sci USA 97:7458-7463

39. Andre P, Prasad KS, Denis CV et al (2002) CD40L stabilizes arterial thrombi by a beta3 integrin-dependent mechanism. Nat Med 8:247-252 